Participants, who were pre-selected, were privy to scenarios/ resources/guidelines beforehand.

Considering restrictions, due to COVID19 outbreak, we implemented video sessions to reduce the number of observers present while extending education to the full complement of both faculties.

Results Based on pre/post-simulation questionnaires, over $70 \%$ of participants reported the simulations improved their skillset and they felt more confident in participating in future; $100 \%$ now felt better equipped to manage Paediatric Emergencies. Engagement in the video streaming was most encouraging, in an era of social distancing and virtual based education.

Conclusion In conclusion, implementing a novel approach to an innovative and multidisciplinary education programme, through the modality of in-situ simulation, can enhance the learning experience and broaden the knowledge base, of NCHDs. We hope that our experience may be used as foresight by others in developing their own multidisciplinary insitu programme.

\section{ETHICAL CONTENT OF GUIDELINES FOR END-OF-LIFE DECISION-MAKING IN PEDIATRIC AND NEONATAL INTENSIVE CARE UNITS: A SYSTEMATIC REVIEW}

Sunčana Janković*, Dina Vrkić, Marko Ćurković, Bojana Nevajdić, Milivoj Novak, Štefan Grosek, Chris Gastmans, Bert Gordijn, Branka Polić, Ana Borovečki. University hospital center Zagreb, Croatia

\subsection{6/archdischild-2021-europaediatrics.340}

The aim of this study was to search for all available reviews, guidelines and analyses and make a literature overview and comparison between countries as a corner stone for a further research with a goal of making our national pediatric and neonatal end-of-life guidelines.

We conducted a literature search in February 2018 and in September 2019 in bibliographic databases and grey literature sources for the time period from 1990 to 2019. Search strategies in were conducted using $\mathrm{MeSH}$ terms and keywords related to 'pediatric', 'neonatal', guidelines', 'end of life', 'palliative care' and 'intensive care unit' terms. Only documents satisfying all of the inclusion and exclusion criteria were included in the review. This resulted in 12 eligible documents.

Ten papers talk about neonatal and four about pediatric issues. Throughout all analyzed papers all of the ethical principles and dilemmas have been mentioned. Best interest model and judicial clarification when parental and physician views collide; doctrines of double effect and omission for withholding and withdrawing of treatment; active and passive euthanasia; quality of life from patient's/parent's and physician's point of view; autonomy and autonomy by proxy; veracity as an informed consent due to shared decision making process; professional duty; beneficence; compassion and nonmaleficence for alleviate suffering; transparency as concealing medical records or documenting detailed plans of care; equality, fairness, social justice and proportionality through treatment justification and allocation of resources for expensive process of treatment or collective society ethics to prevent creation of handicaps; efficacy; utility.

By many means pediatric population is very specific as well as relationship that pediatricians build with children as patients and their parents. Death after forgoing life-sustaining- treatment in intensive care unit occurs through a procedure conforming to national ethical guidelines which in turn seem appropriate for newborn infants and children. Subjectivity regarding indirect euthanasia seems unavoidable. Systematic teaching of ethics to all intensive care staff and continued review processes of end-of-life situations are necessary to preserve the best interests of the critically ill children and relieve their families. The degree of involvement of the parents in the decision-making process varies according to cultural factors and to the structure and functioning of the medical team in charge.

*This article is part of the research 'Values and Decisions at the End of Life', funded by Croatian Science Foundation.

\section{CLINICAL CONTENT OF GUIDELINES FOR END-OF-LIFE DECISION-MAKING IN PEDIATRIC AND NEONATAL INTENSIVE CARE UNITS: A SYSTEMATIC REVIEW}

Sunčana Janković*, Dina Vrkić, Marko Ćurković, Antonija Janković, Milivoj Novak, Štefan Grosek, Chris Gastmans, Bert Gordijn, Branka Polić, Ana Borovečki. University hospital center Zagreb, Croatia

\subsection{6/archdischild-2021-europaediatrics.341}

The aim of this study was to search for all available reviews, guidelines and analyses and make a literature overview and comparison between countries as a corner stone for a further research with a goal of making our national pediatric and neonatal end-of-life guidelines.

We conducted a literature search in February 2018 and in September 2019 in bibliographic databases and grey literature sources for the time period from 1990 to 2019. Search strategies in were conducted using $\mathrm{MeSH}$ terms and keywords related to 'pediatric', 'neonatal', guidelines', 'end of life', 'palliative care' and 'intensive care unit' terms. Only documents satisfying all of the inclusion and exclusion criteria were included in the review. This resulted in 11 eligible documents.

Most of the articles, eight of them are focused on neonatal issues and only three mention specificity of pediatric problems. Among all articles five are general guidelines with examples of diagnosis, five have week by week algorithm and classification of neonatal interventions and three have obstetrical algorithms of prenatal interventions, one article talks about perinatal prognostic factors, four about starting provisional intensive care and reassessment when in doubtful cases, six have a list of clinical procedures in end-of-life decisions, four articles point out a prevalence of neurological impairment after survival as a relevant clinical factor in future end-of-life decisions, four tackle with question of active euthanasia, two recommend palliative care after forgoing life-sustaining treatment with examples of diagnosis, three distinguish different modes of forgoing life-sustaining treatment and two mention organ donation after death.

Clinical guidelines on EOLD are intended as a general framework to help all decision-making parties, but because of uniqueness of every physician, parent, child, diagnosis and underlaying background there are still grey zones that tackle with ethical issues and individual decisions outside the guidelines are always possible.

*This article is part of the research 'Values and Decisions at the End of Life', funded by Croatian Science Foundation. 